\title{
Keanelkaragaman Echinodermata di Pantai Basaan Satu Kecamatan Ratatotok Sulawesi Utara
}

\author{
Chika Christianti Budimana* ${ }^{*}$ Pience V. Maabuata, \\ Marnix L.D Langoy a, Deidy Y. Katilia
}

aJurusan Biologi, FMIPA, Unsrat, Manado

\begin{tabular}{|c|c|}
\hline KATA KUNCI & A B S T R A K \\
\hline $\begin{array}{l}\text { Keanekaragaman } \\
\text { Echinodermata } \\
\text { Pantai Basaan Satu }\end{array}$ & $\begin{array}{l}\text { Keanekaragaman fauna banyak ditemukan di ekosistem pesisir. } \\
\text { Salah satu Filum yang memiliki daya tarik tersendiri di lingkungan pesisir } \\
\text { yaitu Echinodermata. Berdasarkan informasi dan data yang diperoleh, di } \\
\text { Pantai Basaan Satu Kecamatan Ratatotok Sulawesi Utara belum pernah } \\
\text { ada penelitian Echinodermata sebelumnya. Pengambilan sampel } \\
\text { menggunakan metode Purposive Random Sampling dan metode kuadrat. } \\
\text { Hasil Penelitian didapatkan } 13 \text { spesies Echinodermata yaitu kelas } \\
\text { Asteroidea diwakili oleh Linckia laevigata, Protoreaster nodosus dan } \\
\text { Nardoa tuberculata. Ophiomastix annulosa termasuk pada kelas } \\
\text { Ophiuroidea. Kelas Echinoidea diwakili oleh Diadema setosum, } \\
\text { Tripneustes gratilla, Echinometra mathaei, Echinothrix diadema dan } \\
\text { Echinothrix calamaris. Kelas Holothuroidea diwakili oleh Synapta } \\
\text { maculata, Holothuria atra, Holothuria scabra dan Bohadschia marmmota. } \\
\text { Indeks keanekaragaman Echinodermata sedang ditemukan pada habitat } \\
\text { mangrove yaitu H'=1,21 dan habitat terumbu karang H'=1,97, sedangkan } \\
\text { pada habitat padang lamun indeks keanekaragamannya rendah dengan } \\
\text { H'=0,88. }\end{array}$ \\
\hline
\end{tabular}

K E Y W O R D S

Diversity

Echinoderms

Basaan Satu Beach

\section{A B S T R A C T}

The animal diversity can be found in beach-side ecosystem. One of animal phylum wich has its own uniqueness is Echinoderms. According to the information and data, in Basaan Satu beach, Ratatotok district, North Sulawesi, there's no research related to Echinoderms has been done there yet. Method used in sampling was Purposive Random Sampling and square method. In this research, 13 species of Echinoderms were found. They are Linckia laevigata, Protoreaster nodosus and Nardoa tuberculata from Asteroidea class. Ophiomastix annulosa from Ophiuroidea class. Diadema setosum, Tripneustes gratilla, Echinometra mathaei, Echinothrix diadema and Echinothrix calamaris from Echinoidea class. Synapta maculata, Holothuria atra, Holothuria scabra and Bohadschia marmmota from Holothuroidea class. Diversity index of Echinoderms in mangrove habitat and coral habitat are moderate $\left(H^{\prime}=1,21\right.$ and $H^{\prime}=1,97$, respectively), while in seagrass habitat it is low $\left(\mathrm{H}^{\prime}=0,88\right)$.

\section{TERSEDIA ONLINE}

20 Oktober 2014

\section{Pendahuluan}

Wilayah pesisir Indonesia memiliki sumber daya perairan yang tinggi, seperti keanekaragaman fauna. Keanekaragaman fauna yang banyak ditemukan di lingkungan pesisir adalah fauna Echinodermata (Herman, 2004). 
Echinodermata berasal dari bahasa Yunani Echinos artinya duri, derma artinya kulit. Echinodermata adalah penghuni perairan dangkal, umumnya terdapat di terumbu karang dan padang lamun. Hewan ini memiliki kemampuan autotomi serta regenerasi bagian tubuh yang hilang, putus atau rusak. Semua hewan yang termasuk dalam kelas ini memiliki bentuk tubuh yang radial simetris dan kebanyakan mempunyai endoskeleton dari zat kapur seperti tonjolan berupa duri (Jasin, 1984).

Pantai Basaan Satu terletak di Kecamatan Ratatotok, Kabupaten Minahasa Tenggara, Sulawesi Utara. Pantai ini memiliki daerah mangrove, padang lamun dan terumbu karang.

\section{Metode}

Penelitian ini dilaksanakan pada bulan Mei sampai Juli 2014 di Pantai Basaan Satu Kecamatan Ratatotok, Kabupaten Minahasa Tenggara, Sulawesi Utara.

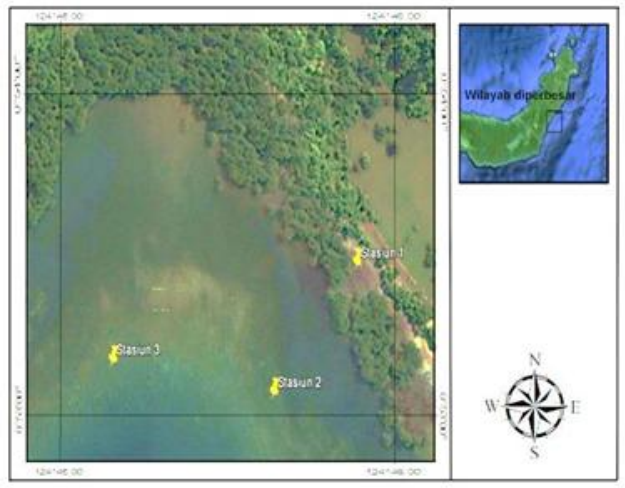

Pengambilan sampel di lokasi penelitian dilakukan pada saat surut terendah hingga air mulai pasang dengan menggunakan metode purposive random sampling dan metoda kuadrat. Penentuan stasiun berdasarkan keterwakilan masing-masing ekosistem, yaitu mangrove, padang lamun dan terumbu karang.

Sampel yang diketahui langsung diidentifikasi di lapangan dan yang belum teridentifikasi diambil dan dibawa untuk diidentifikasi di laboratorium Ekologi FMIPA Unsrat Manado. Identifikasi dilakukan dengan menggunakan buku identifikasi dari Susetiono (2004).

Analisis data yang ]digunakan yaitu Kepadatan (K), Kepadatan relatif (KR), Frekuensi (F), Frekuensi Relatif (FR), Indeks keanekaragaman spesies ( $\mathrm{H} \square$ ), Indeks kemerataan spesies (E).

\section{Hasil dan Pembahasan}

\subsection{Karakteristik Lokasi Penelitian}

Kondisi lokasi penelitian terbagi atas tiga jenis ekosistem yaitu daerah mangrove, daerah pasir putih yang ditumbuhi beberapa jenis lamun dan daerah terumbu karang. Letak geografi di lokasi penelitian Desa Basaan Satu Kecamatan Ratatotok Kabupaten Minahasa Tenggara Provinsi Sulawesi
Utara yaitu pada Stasiun I di daerah mangrove (0053'37'59'LU dan 12445'33'54'BT) bersubstrat pasir berlumpur dan ditumbuhi jenis mangrove Sonneratia alba, Rhizophora mucronata dan Rhizophora stylosa. Stasiun II (0053'35'83'LU dan $\left.124^{\circ} 45^{\prime} 31^{\prime} 81^{\prime} B T\right)$ merupakan daerah bersubstrat pasir putih yang ditumbuhi jenis lamun Halophila ovalis, Enhalus acoroides, dan Thalasia hemprichii. Stasiun III di terumbu karang (0053'36'28'LU dan 124 $\left.{ }^{\circ} 45^{\prime} 28^{\prime} 51^{\prime} \mathrm{BT}\right)$ merupakan daerah rataan karang, terlihat karang mati dan karang hidup berada di tempat tersebut. Jenis karang yang ada di lokasi pengambilan sampel tersebut yaitu dari Famili Poritidae dan Famili Faviidae.

Hasil pengukuran faktor fisik dan kimia menunjukkan suhu pada saat pengambilan sampel 28-32 ${ }^{\circ} \mathrm{C}$, kecerahan 0,21-0,45 cm, salinitas 32-34 ppt dan pH 7. Kondisi faktor lingkungan ini masih termasuk baik sesuai dengan standard baku mutu air laut, yaitu suhu $28-32^{\circ} \mathrm{C}$, kecerahan $3-5 \mathrm{~m}$, salinitas 32-34 ppt dan $\mathrm{pH}$ 7-8,5.

\subsection{Distribusi dan Jenis Echinodermata}

Hasil penelitian di Pantai Basaan Satu diperoleh 13 spesies Echinodermata yang termasuk dalam 4 kelas yaitu kelas Asteroidea diwakili oleh Linckia laevigata, Protoreaster nodosus, dan Nardoa tuberculata. Ophiomastix annulosa termasuk pada kelas Ophiuroidea. Kelas Echinoidea diwakili oleh Diadema setosum, Tripneustes gratilla, Echinometra mathaei, Echinothrix diadema dan Echinothrix calamaris. Kelas Holothuroidea diwakili oleh Synapta maculata, Holothuria atra, Holothuria scabra, dan Bohadschia marmmota.

Spesies yang terdistribusi pada semua habitat yaitu S. maculata dikarenakan spesies ini mampu bertahan hidup pada semua zona yang ada di laut. Ketiga habitat ini berperan besar dalam menyediakan makanan, tempat perlindungan dan berbagai bentuk kebutuhan lainnya sehingga mempengaruhi keberadaan spesies ini. Menurut Yusron (2009), kehadiran teripang pada ketiga mikrohabitat tersebut salah satunya karena kebutuhan akan perlindungan dari sinar matahari.

Total semua jumlah individu dari ketiga habitat yaitu 177 individu. Habitat padang lamun merupakan habitat yang memiliki jumlah individu tertinggi dibandingkan dua habitat lainnya, dengan jumlah 71 individu, diikuti oleh habitat terumbu karang 63 individu dan yang memiliki jumlah individu terendah pada habitat mangrove dengan jumlah 43 individu.

Habitat mangrove ditemukan 2 spesies yang tinggi jumlah individunya, dari kelas Echinoidea yaitu $D$. setosum 22 individu dan E. calamaris 10 individu. Diduga akar pohon mangrove merupakan faktor pendukung keberadaan spesies $D$. setosum, karena dapat digunakan untuk melindungi diri dari gelombang laut. Hal ini didukung oleh Irwanto (2006) bahwa sistem perakaran mangrove juga 
menjadi tempat perlindungan, mengasuh dan membesarkan biota laut.

Spesies S. maculata dari kelas Holothuroidea ditemukan pada habitat padang lamun, spesies ini memiliki jumlah individu tertinggi di habitat tersebut yaitu berjumlah 52 individu. Hal ini dimungkinkan pada habitat padang lamun dijadikan sebagai tempat hidup dan penyedia makanan bagi spesies ini dalam bentuk detritus sehingga banyak spesies ini yang hidup di daerah tersebut. Menurut Pratiwi (2010), banyaknya organisme secara ekologis dan biologis sangat tergantung pada keberadaan lamun. Ekosistem lamun merupakan sumber makanan penting bagi banyak organisme oleh sebab itu banyak biota Echinodermata yang memanfaatkannya sebagai tempat memijah.

Habitat terumbu karang terlihat jumlah individu tertinggi adalah $D$. setosum dan S. maculata yaitu 14 individu. Menurut Yusron (2006), fauna Echinodermata hidup di daerah karang karena daerah ini merupakan salah satu ekosistem yang penting bagi kehidupan spesies pemakan detritus dan melindungi diri dari predator. Sesuai dengan fungsi dari terumbu karang yaitu sebagai tempat berlindung dan sumber makanan bagi spesies.

\subsection{Kepadatan dan Kepadatan relatif Filum Echinodermata}

Spesies $D$. setosum memiliki kepadatan tertinggi pada habitat mangrove dengan jumlah 1,10 individu/ $\mathrm{m}^{2}$ dan kepadatan relatif $51,16 \%$. Spesies $D$. setosum banyak terdapat di daerah mangrove karena spesies ini hidup berkelompok dan menempel pada celah-celah akar mangrove untuk beradaptasi melindungi diri terhadap perubahan suhu dan hempasan ombak yang keras agar tidak terbawa oleh gelombang laut. Karakteristik dari spesies ini yaitu hidup menyebar hampir pada semua zona yang ada di laut (Rumahlatu et al., 2008). Kepadatan terendah terdapat pada spesies $S$. maculata dengan jumlah kepadatan 0,25 individu/ $\mathrm{m}^{2}$ dan kepadatan relatif $11,63 \%$. Diduga keberadaan S. maculata di stasiun ini karena terbawa oleh arus laut. Habitat mangrove memiliki frekuensi tertinggi 0,40 dan frekuensi relatif $34,78 \%$ pada spesies E. calamaris. Frekuensi terendah pada spesies 0 . annulosa dengan jumlah 0,15 dan frekuensi relatif $13,04 \%$. Spesies 0 . annulosa dapat menempati dasar berlumpur, berpasir atau campuran lumpur dan pasir (Aziz, 1991). Namun terlihat dengan jelas pada pengambilan sampel bahwa spesies 0 . annulosa sedikit ditemukan karena pada daerah mangrove yang berada di lokasi pantai ini sudah banyak ditebang pohon mangrove yang menjadi habitat dari spesies ini

Habitat padang lamun terdapat kepadatan tertinggi pada spesies $S$. maculata yaitu 2,60 individu/ $\mathrm{m}^{2}$ dengan kepadatan relatif $73,24 \%$ dan frekuensi tertinggi 1,05 dan frekuensi relatif $60,00 \%$. Tingginya frekuensi kehadiran spesies ini disebabkan oleh tingginya ketersediaan jumlah makanan utama spesies tersebut yang berada di lamun. Menurut Yusron dan Susetiono (2010), kehadiran individu teripang ini pada daerah padang lamun bercampur pasir putih untuk berlindung dari sinar matahari.

Kepadatan terendah 0,05 individu/ $\mathrm{m}^{2}$ dengan kepadatan relatif $1,41 \%$ terdapat pada spesies $T$. gratilla dan $H$. scabra dan frekuensi terendah 0,05 dengan frekuensi relatif $2,86 \%$, hal ini dikarenakan jumlah individu kedua spesies ini hanya didapati 1 individu saat pengambilan sampel dan hanya berada pada satu plot saja. Berkurangnya presentase spesies ini dipengaruhi oleh jumlah kehadirannya dalam habitat, frekuensi kehadirannya berkurang disebabkan pengambilan terus menerus oleh masyarakat sehingga menurunkan daya reproduksi (Rumahlatu et al., 2008).

Habitat terumbu karang terdapat kepadatan tertinggi pada spesies $D$. setosum dan S. maculata yaitu 0,70 individu/ $\mathrm{m}^{2}$ dan kepadatan relatif $22,22 \%$. Hal ini dikarenakan habitat ini adalah habitat yang cocok untuk kedua spesies ini, yaitu terumbu karang yang memiliki substrat keras agar dapat bertahan hidup pada bebatuan karang. Frekuensi tertinggi 0,55 dan frekuensi relatif 23,40\% terdapat pada Linckia laevigata, dapat dikatakan bahwa di stasiun ini adalah daerah hidup dari spesies ini dengan cara menempel pada bebatuan atau karang untuk mempertahankan hidupnya, sehingga banyak kemunculan spesies ini pada habitat terumbu karang. Kepadatan terendah 0,05 individu/ $\mathrm{m}^{2}$ dan kepadatan relatif $1,59 \%$ terdapat pada $O$. annulosa dan E. calamaris, kemudian untuk frekuensi terendah yaitu 0,05 dan frekuensi relatif 2,13\% terdapat pada spesies yang sama. Hal ini dimungkinkan karena biota ini tidak memiliki nilai ekonomis sehingga faktor eksploitasi terhadap jenis ini sangat rendah (Aziz, 1991).

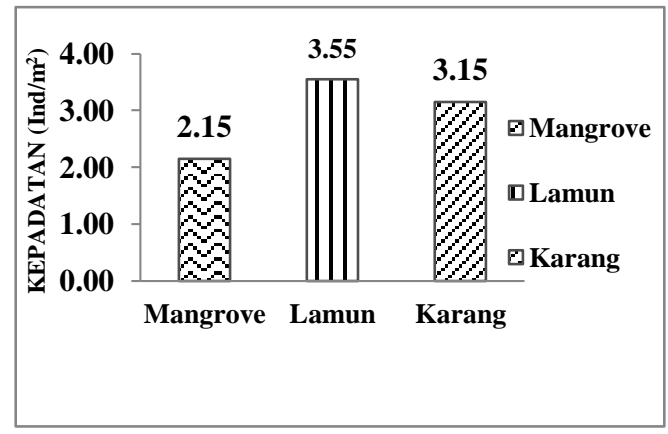

Gambar 1. Kepadatan

Rata-rata kepadatan spesies tertinggi yaitu 3,55 individu/ $\mathrm{m}^{2}$ berada di habitat padang lamun dan spesies S. maculata merupakan spesies yang memiliki kepadatan rata-rata tertinggi dibandingkan dari spesies Echinodermata lainnya. S. maculata ini merupakan jenis non komersial yang tidak ditangkap oleh para nelayan sehingga dapat berkembang lebih baik dibandingkan teripang jenis lain. Spesies ini menyukai dasar berpasir halus dengan tumbuhan lamun untuk dijadikan tempat 
perlindungan dari hempasan ombak dan lingkungannya kaya akan detritus. Spesies ini juga dapat menempati habitat tergenang air bahkan saat surut (Darsono, 2007).

Kepadatan terendah rata-rata terdapat pada habitat mangrove yaitu 2,15 individu/ $\mathrm{m}^{2}$. Diduga kurangnya fauna Echinodermata yang berada di daerah mangrove disebabkan karena penangkapan secara terus menerus oleh masyarakat untuk dijadikan bahan konsumsi dan perdagangan. Selain itu faktor lain yang mempengaruhi rendahnya nilai kepadatan dari Echinodermata salah satunya disebabkan karena kurangnya kemampuan bersaing dalam menempati suatu habitat (Radjab, 2001).

\subsection{Indeks Keanekaragaman Echinodermata}

Indeks keanekaragaman terlihat untuk stasiun I (habitat mangrove) yaitu $\mathrm{H}^{\prime}=1,21$, stasiun II (habitat padang lamun) yaitu $\mathrm{H}^{\prime}=0,88$, dan stasiun III (habitat terumbu karang) yaitu $H^{\prime}=1,97$. Hasil menunjukkan bahwa nilai $1 \leq \mathrm{H} \square \leq 3$ untuk habitat mangrove dan terumbu karang termasuk keanekaragaman spesies sedang, sedangkan untuk habitat padang lamun menunjukkan keanekaragaman spesies rendah dengan nilai $\mathrm{H} \square$ $<$ 1. Diduga bahwa di habitat padang lamun menunjukkan keanekaragaman rendah karena didaerah tersebut ada 1 spesies yang lebih mendominasi yaitu S.maculata.

Hal ini didukung oleh Supono dan Arbi (2010) bahwa, tinggi rendahnya nilai indeks keanekaragaman jenis dapat disebabkan oleh berbagai faktor, yaitu jumlah jenis atau individu yang didapat, adanya beberapa jenis yang ditemukan dalam jumlah yang melimpah, homogenitas substrat dan kondisi dari tiga ekosistem penting di daerah pesisir yaitu padang lamun, terumbu karang dan hutan mangrove sebagai habitat biota perairan.

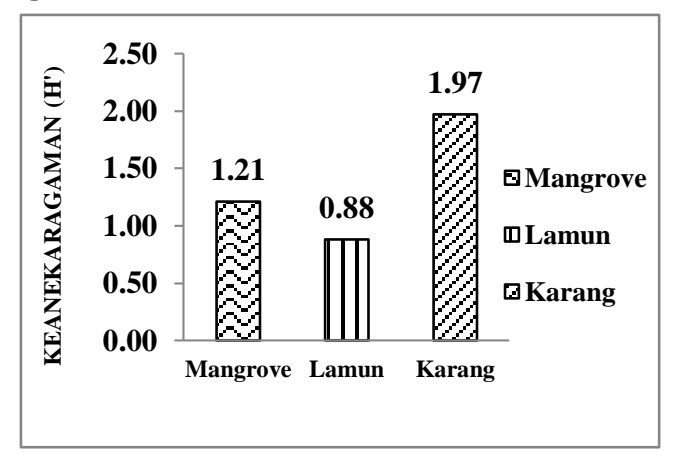

Gambar 2. Indeks Keanekaragaman.

\subsection{Indeks Kemerataan Filum Echinodermata}

Nilai indeks kemerataan pada ketiga stasiun ini berbeda-beda. Pada habitat mangrove memiliki nilai indeks kemerataan tertinggi $\mathrm{E}=0,87$, diikuti habitat terumbu karang dengan nilai indeks kemerataan $\mathrm{E}=0,86$ dan habitat padang lamun memiliki nilai indeks kemerataan terendah $\mathrm{E}=0,49$. Data yang diperoleh menunjukkan bahwa pada habitat mangrove dan habitat terumbu karang memiliki kemerataan tertinggi disebabkan karena penyebaran individu tiap spesies sama atau hampir sama ditemukan, sedangkan pada indeks kemerataan yang rendah ditemukan pada habitat padang lamun disebabkan karena penyebaran individu tiap spesies tidak menyebar merata, sebab di habitat ini hanya terlihat salah satu spesies yang hidup sangat melimpah jumlah individunya.

Krebs (1989) menyebutkan bahwa jika spesiesspesies yang ditemukan pada suatu komunitas memiliki jumlah individu tiap spesies yang sama atau hampir sama, maka kemerataan di komunitas tersebut menjadi tinggi. Ketidakmerataan jenis Echinodermata tersebut diduga disebabkan oleh penyebaran jumlah individu tiap jenis tidak menyebar secara merata, atau disebabkan karena faktor fisik-kimia lingkungan.

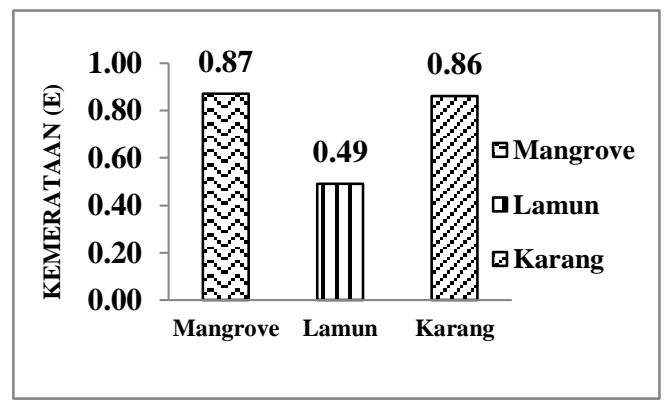

Gambar 3. Indeks Kemerataan.

\section{Kesimpulan}

Nilai indeks keanekaragaman sedang pada habitat mangrove yaitu $\mathrm{H}^{\prime}=1,21$ dan habitat terumbu karang $\mathrm{H}^{\prime}=1,97$, sedangkan pada habitat padang lamun $\mathrm{H}^{\prime}=0,88$ indeks keanekargamannya rendah. Jenis Echinodermata di pantai Basaan Satu Kecamatan Ratatotok Sulawesi Utara ditemukan 13 spesies, untuk kelas Asteroidea (Linckia laevigata, Protoreaster nodosus, dan Nardoa tuberculata), kelas Ophiuroidea (Ophiomastix annulosa), kelas Echinoidea (Diadema setosum, Tripneustes gratilla, Echinometra mathaei, Echinothrix diadema, dan Echinothrix calamaris), kelas Holothuroidea (Synapta maculata, Holothuria atra, Holothuria scabra, dan Bohadschia marmmota).

\section{Daftar Pustaka}

Aziz, A. 1991. Beberapa Catatan Tentang Bintang Mengular (Ophiuroidea) Sebagai Biota Bentik. Oseana. XVI (1): 13-22.

Darsono, P. 2007. Teripang (Holothuroidea): Kekayaan Alam Dalam Keragaman Biota Laut. Oseana. XXXII (2): 1-10.

Herman. 2004. Sebaran dan asosiasi makroepifauna pada ekosistem padang lamun di perairan pulau tidung besar, kepulauan seribu, Jakarta Utara [Skripsi]. Program Studi IImu Kelautan, Departemen IImu dan Teknologi Kelautan. Institut Pertanian Bogor. Bogor 
Irwanto. 2006. Keanekaragaman Fauna Pada Habitat Mangrove. http//www.geocities.com/ irwantoforester/fauna_mangrove.pdf. [22 Agustus 2014].

Jasin, M. 1984. Sistematika Hewan (Invertebrata dan Vertebrata). Sinar Wijaya. Surabaya.

Krebs, C. J. 1989. Ecological Methodology. Harper and Row. New York.

Pratiwi, R. 2010. Asosiasi Krustasea di Ekosistem Padang Lamun Perairan Teluk Lampung. IImu Kelautan. 15 (2): 66-76.

Radjab A.W. 2001. Reproduksi dan Siklus Bulu Babi (Echinoidea). Oseana. XXVI (3): 25-36.

Rumahlatu, D., Gofur, A. dan Sutomo, H. 2008. Hubungan Faktor Fisika - Kimia Lingkungan Dengan Keanekaragaman Echinodermata Pada Daerah Pasang Negeri Malang. 37 (1): 77-85.
Supono dan Arbi, U.Y. 2010. Struktur Komunitas Ekhinodermata Di Padang Lamun Perairan Kema, Sulawesi Utara. Oseanologi dan Limnologi di Indonesia. 36 (3): 329-342.

Susetiono. 2004. Fauna Padang Lamun Tanjung Merah Selat Lembeh. Pusat Penelitian Oseanografi, LIPI. Cibinong.

Yusron, E. 2006. Biodiversitas Ekhinodermata Di Perairan Pantai Takofi, Pulau Moti-Maluku Utara. Makara Sains. 10 (1):41-46.

Yusron, E. 2009. Keanekaragaman Jenis Echinodermata Di Perairan Teluk Kuta, Nusa Tenggara Barat. Makara, Sains. 13 (1): 45.

Yusron, E dan Susetiono. 2010. Diversitas Fauna Ekhinodermata Di Perairan Ternate- Maluku Utara. Oseanologi dan Limnologi di Indonesia. 36 (3): 294-295. 